\title{
FORMAÇÃO DO ENFERMEIRO: DESAFIOS PARA A PROMOÇÃO DA SAÚDE
}

\author{
Nurse training: challenges for health promotion \\ La formación del enfermero: retos para la promoción de la \\ salud
}

Kênia Lara Silva ${ }^{1}$

Roseni Rosângela de Sena²

Maria José Cabral Grillo ${ }^{3}$

Natália de Cássia Horta ${ }^{4}$

\section{RESUMO}

Estudo qualitativo, descritivo-exploratório, realizado em dois cursos de Enfermagem com o objetivo de analisar os referenciais de promoção da saúde na formação do enfermeiro. Foram entrevistados 19 coordenadores, docentes, estudantes e profissionais de serviços envolvidos na formação do enfermeiro. Os resultados indicam imprecisão conceitual entre promoção da saúde e prevenção de agravos na formação do enfermeiro. As concepções de promoção da saúde reveladas estão associadas a práticas que incidem sobre qualidade de vida sustentada em um conceito amplo e complexo de saúde e que são incipientes nos cenários da atenção à saúde. Conclui-se que a promoção da saúde é tomada como decisão política para mudança na formação do enfermeiro, explicitada nos projetos pedagógicos das instituições cenário do estudo. Entretanto, esta incorporação é incipiente e heterogênea quanto à formulação teórica, indicando a necessidade de ampliação dos espaços de análise conceitual nas relações que proporcionam a produção de saúde e do processo formativo.

Palavras-chave: Educação em Enfermagem. Currículo. Promoção da Saúde.

\begin{abstract}
This was a descriptive/exploratory study of qualitative character carried out in two Nursing Schools in the State of Minas Gerais. The goal was to analyze the referential of nurses regarding health promotion. Nineteen course coordinators, faculty members, students and professionals of the health services involved in nurse training were interviewed. The results indicate a conceptual imprecision about health promotion and disease prevention. Revealed conceptions of health-promoting practices are associated to practices that affect the quality of life, which lies on a broad and complex concept of health, and are incipient in the current health care scenario. The conclusion is that health promotion is taken as political decision for a change in nurse training, as made explicit in the pedagogical projects of the institutions taking part in the study. However, such incorporation is incipient and heterogeneous in terms of its theoretical formulation, thus indicating the need for widening the space for a conceptual analysis in the relations that allow for the production of health and of a training process.
\end{abstract}

Keywords: Nursing Education. Curriculum. Health Promotion.

\section{Resumen}

Estudio cualitativo de tipo descriptivo y exploratorio realizado en dos cursos de enfermería con el objeto de analizar los puntos de referencia de la promoción de la salud en la formación del enfermero. Se entrevistaron a 19 coordinadores, profesores, estudiantes y profesionales de las áreas que participan en la educación y formación del personal de enfermería. Los resultados indican que existe vaguedad conceptual de la promoción de la salud y la prevención de agravamientos en esta formación. El concepto de promoción de la salud está asociado a prácticas de divulgación que se centran en la calidad de vida basada en un concepto amplio y complejo de la salud, incipientes en el ámbito de la asistencia de la salud. Se concluyó que la promoción de la salud se convierte en un instrumento de decisión política que permite realizar cambios en la educación de enfermería puesta de manifiesto en los proyectos de estudio de las instituciones que se enmarcan en esta investigación. Sin embargo, debido a su formulación teórica, esta incorporación es incipiente y heterogénea, confirmando que existe la necesidad de ampliar los espacios para el análisis conceptual dentro del círculo de relaciones que hacen aportes a la producción de la salud y al proceso de formación.

Palabras clave: Educación en Enfermería. Currículo. Promoción de la salud.

\footnotetext{
'Enfermeira. Pesquisadora do NUPEPE, Doutoranda em Enfermagem, Professora do Curso de Enfermagem da PUC Minas.E-mail: kenialara17@yahoo.com.br,' Enfermeira. Doutora em Enfermagem, Coordenadora do NUPEPE. Professora Emérita da Escola de Enfermagem da Universidade Federal de Minas Gerais. Brasil. E-mail: ronesisena@uol.com.br, ${ }^{3}$ Enfermeira. Pesquisadora do NUPEPE, Doutoranda em Enfermagem, Professora do Departamento de Enfermagem Básica da Escola de Enfermagem da Universidade Federal de Minas Gerais. Brasil. E-mail: majo@enf.ufmg.br, ${ }^{4}$ Enfermeira. Pesquisadora do NUPEPE, Doutoranda em Enfermagem, Professora do Curso de Enfermagem da PUC Minas. Brasil. E-mail: nanahorta@yahoo.com.br
} 


\section{INTRODUÇÃO}

0 paradigma biomédico, hegemônico nas práticas de saúde, está sustentado em uma concepção de saúde restrita à dimensão biológica e individual que não permite acionar mecanismos orientados pelas múltiplas necessidades e demandas de saúde da população. Essa situação é foco de debates e definiç̃̃es políticas, principalmente a partir da década de setenta. Nesse período, a promoção da saúde despontou como "nova concepção de saúde", construída nos debates sobre a determinação social e econômica da saúde, e que não se limita a um enfoque centrado na doença. ${ }^{1}$

$\mathrm{Na}$ Conferência Internacional sobre Cuidados Primários de Saúde, realizada em Alma-Ata, em 1978, a busca por um novo modelo de atenção à saúde que possibilitasse "Saúde para todos no ano 2000" criou uma nova agenda para o campo da Saúde. A Declaração de Alma-Ata conclamou governos, organismos a comunidade internacional e todos aqueles que trabalham no campo da saúde a envidar em esforços para que a Atenção Primária em Saúde (APS) fosse priorizada, incluindo a definição de orçamento adequado para o setor.

Em 1986, na Conferência Internacional de Promoção da Saúde, 38 países aprovaram a Carta de Ottawa, um marco no processo de discussão e de construção de um novo modelo de atenção. ${ }^{2}$ A Carta de Ottawa "reafirma a importância da promoção da saúde e aponta, principalmente, a influência dos aspectos sociais sobre a saúde dos indivíduos e da população".'

Adotar a APS como prioridade, em países onde o modelo hegemônico está voltado para a doença e centrado na atenção hospitalar, constitui um grande desafio de desconstrução e reconstrução no setor saúde. No Brasil, o movimento de desconstrução consubstanciou-se no Movimento da Reforma Sanitária Brasileira. Este movimento, entre tantas ideias defendidas, ressaltava a importância da formação de recursos humanos com foco na saúde, em outra perspectiva de abordagem e com uma nova compreensão do processo saúdedoença, e na relação da saúde com as condiç̃es de vida e de trabalho da população. ${ }^{3}$ Os debates realizados na $8^{\text {a }}$ Conferência Nacional de Saúde e, posteriormente, em espaços de articulação da Participação Popular na Constituinte, deram origem ao Sistema Único de Saúde (SUS), com princípios incorporados na Constituição da República, em 1988.

Ao longo das últimas décadas, muitos instrumentos legais foram editados para viabilizar o SUS, ou seja, concretizar seus princípios constitucionais na perspectiva de produzir saúde com qualidade. Neste trabalho, ressaltamos, entre esses instrumentos legais, a Portaria 687 GM/MS, de 30 de março de 2006, que instituiu a Política Nacional de Promoção da Saúde.
Argumentando sobre a importância do paradigma promocional, o Ministério da Saúde destaca a importância da intersetorialidade, definindo-a como uma articulação dos distintos setores em torno do pensar a saúde, de corresponsabilizar-se por sua garantia enquanto direito humano fundamental e de cidadania, e mobilizar-se na formulação de intervenções que a propiciem. ${ }^{4}$ Como estratégia de articulação transversal, a promoção da saúde joga luz sobre os determinantes e condicionantes da saúde - modos de viver, condições de trabalho, habitação, ambiente, educação, lazer, cultura, acesso a bens e serviços essenciais - e a necessidade de considerá-los para reduzir vulnerabilidades e riscos à saúde. ${ }^{4}$ A sua operacionalização deve refletir o compromisso com 0 bem-estar das pessoas, a defesa da equidade e da qualidade de vida da população atual e das gerações futuras, a busca da ampliação das capacidades e possibilidades de escolha individuais e coletivas, a ação local, a afirmação da diversidade e do multiculturalismo e o desenvolvimento de instrumentos de participação popular deliberativa. ${ }^{4}$

A articulação das possibilidades e a corresponsabilidade do campo da formação de recursos humanos em saúde com o paradigma da promoção da saúde éfundamental para fortalecer a consolidação do SUS, tornando cada vez mais concretos seus princípios e diretrizes.

Partindo dessa problemática, realizamos a pesquisa intitulada "Promoção da Saúde: estratégia política, assistencial, educacional e gerencial para a construção do modelo tecnoassistencial em saúde" ", organizada em quatro subprojetos: As políticas públicas de promoção da saúde - da gestão do sistema à articulação intersetorial, Concepções de promoção da saúde na equipe de saúde da família; Abordagem da promoção da saúde na formação do enfermeiro; e Promoção da saúde em espaços sociais da vida cotidiana.

Neste artigo, apresentamos os resultados do subprojeto intitulado "Abordagem da promoção da saúde na formação do enfermeiro". Nosso objetivo geral foi analisar as concepções e práticas de promoção da saúde na formação desse profissional. Definimos como objetivos específicos: identificar as práticas de promoção da saúde desenvolvidas durante a formação, identificar os referenciais teórico-conceituais sobre promoção da saúde que sustentam a formação do enfermeiro e identificar as relações existentes entre ensino-serviço-comunidade para viabilizar as práticas de promoção da saúde.

Partimos do pressuposto de que atuar na promoção da saúde é uma possibilidade de responder a demandas sociais e exige reflexões que perpassam quatro eixos fundamentais: a concepção de saúde, a gestão dos processos de trabalho e educação, a formação dos profissionais de saúde, a participação 


\section{Formação do enfermeiro:desafios para a promoção da saúde}

e o controle social. A conjugação desses eixos deve direcionar as práticas em saúde, imprimindo a lógica do modelo tecnoassistencial em constante construção e reconstrução. Essa premissa resgata a imagem de um quadrilátero para a formação em saúde em que ensino, gestão setorial, práticas de atenção e controle social se articulam para construir e organizar uma educação responsável por processos interativos e de ação na realidade. Essa ação deve operar mudanças (desejo de futuro), mobilizar caminhos (negociar e pactuar processos), convocar protagonismos (pedagogia in acto) e detectar a paisagem interativa e móvel, de indivíduos, coletivos e instituições, como cenário de conhecimentos e invenções (cartografia permanente). ${ }^{5}$

Eleger os referenciais de promoção da saúde para a ressignificação do ensino de enfermagem implica transformar as práticas de ensino, superando o modelo biologicista e a natureza setorial que caracteriza a formação e a atuação dos profissionais de saúde. Agrega-se a necessidade de fomentar as mudanças com a incorporação de conceitos como interdisciplinaridade, intersetorialidade, potencialização de sujeitos e qualidade de vida, entendidos como elementos que devem sustentar uma nova prática de formação e atuação que tenham como referencial a promoção da saúde. ${ }^{6}$ Para tanto, é preciso que o processo ensino-aprendizagem em enfermagem favoreça as práticas educacionais e de atenção à saúde que potencializem os sujeitos para atuarem na efetivação das mudanças sociais. Souza et al. 1:256 afirmam que "a interação dos estudantes com a população no seu contexto social assim como a cooperação estudante-docente mostram-se importantes para 0 processo de ensino-aprendizagem e para 0 desenvolvimento da autonomia profissional". Assim sendo, as mudanças devem ter como base práticas que propiciem um movimento dinâmico e de permanente ressignificação do conhecimento, de aquisição de habilidades e de atitudes que 0 faça mais capaz para a vida e para o trabalho, assumindo-se, assim, a concepção e método da educação crítico-reflexiva. ${ }^{8-9}$

\section{METÓDOS}

0 estudo caracteriza-se como descritivo-exploratório, com abordagem qualitativa, orientado pela concepção teóricofilosófica da dialética. As questões éticas foram observadas em todas as etapas da pesquisa, tendo sido aprovada no Comitê de Ética em Pesquisa da Universidade Federal de Minas Gerais sob parecer número 463/06.

Os cenários da pesquisa foram dois cursos de graduação em enfermagem do Estado de Minas Gerais/Brasil: uma instituição privada e uma instituição pública. Em uma primeira fase, foram entrevistadas duas docentes em cargos de gestão nos dois cursos, utilizando-se um roteiro semiestruturado. No momento da entrevista, foi solicitado às docentes-coordenadoras que indicassem situações marcadoras de aprendizagem para a promoção da saúde, vivenciadas pelos estudantes, docentes e profissionais envolvidos no processo de formação de sua instituição. A segunda etapa da coleta de dados consistiu na verificação in loco das situações marcadoras indicadas pelas coordenadoras entrevistadas, resultando em entrevistas com 2 docentes, 5 estudantes e 8 profissionais dos serviços de saúde que recebem os estudantes de enfermagem, 1 coordenador de projeto social e 1 presidente de Conselho Local de Saúde. Em ambos os cenários foram realizadas visitas nos serviços e nas comunidades nas quais aconteciam as ações de ensino e de aprendizagem. Em um dos cenários foram propiciados dois momentos diferenciados de análise: uma roda de discussão com uma equipe de saúde da família e uma reunião do Conselho Local de Saúde. Nesse cenário também ocorreram entrevistas com dirigentes municipais responsáveis pela articulação ensinoserviço. No outro cenário foram realizadas observações na unidade local de saúde e em uma instituição não governamental, cenários de aprendizagem dos estudantes. Todos os registros das observações foram anotados no Diário de Campo e subsidiaram a análise dos dados. Destaca-se que as experiências marcadoras indicadas pelos docentes foram o estágio supervisionado, realizado no final do curso.

Para a análise dos dados empíricos, utilizou-se a técnica de análise de discurso. Foram realizadas leituras exaustivas dos discursos buscando apreender as ideias centrais, ou seja, estruturas de significados presentes nas falas dos participantes. 0 agrupamento das ideias centrais deu origem a uma rede de significados relacionados com as políticas e as ações pedagógicas que favorecem a incorporação de concepções e práticas de promoção da saúde na formação do enfermeiro, nas instituiç̧̃̃es cenários do estudo.

Para se garantir o anonimato, foram atribuídos códigos aos entrevistados, compostos por letras antecedidas e seguidas de um número, como, por exemplo, 5W2. As letras W, X, Y, Z e IF representam respectivamente: estudante, docente, profissional de serviço, professor em cargo de coordenação no curso e informante-chave. 0 número após a letra representa a sequência de realização das entrevistas por categoria ( 1 a 5 por estudante, 1 e 2 por docente, 1 a 8 para profissionais do serviço, 1 a 3 para professores em cargo de coordenação e 1 a 3 para os informantes-chave). 0 número antecedente da letra representa a frase temática da decomposição do discurso.

A etapa final da análise consistiu na interpretação dos dados empíricos, estabelecendo diálogos com os autores consultados e a experiência e conhecimento das pesquisadoras, 
em um movimento dialético, visando o concreto pensado, revelando a diversidade e as especificidades nas concepções de promoção da saúde que se expressam na formação do enfermeiro.

A rede de significados foi analisada de acordo com os objetivos do estudo e, neste artigo, focamos os analisadores referentes à abordagem conceitual de promoção da saúde e os requisitos para a promoção da saúde na formação do profissional enfermeiro, bem como a política e ações pedagógicas que favorecem a incorporação de concepções e práticas de promoção da saúde na formação, articulados com o cotidiano dos serviços de saúde.

\section{RESULTADO E DISCUSSÃO}

A análise dos discursos permitiu identificar a diversidade de concepções e práticas de promoção da saúde presentes na formação do enfermeiro. Partindo-se do campo teórico, nota-se um amplo foco da temática de promoção da saúde e a coexistência de referenciais de saúde que vão desde um campo de saúde versus doença até a qualidade de vida e a participação da comunidade. Essa afirmação sustenta-se na amplitude do conceito de promoção da saúde explicitado e abordado no processo de formação:

Esta discussão, do que é promoção da saúde e qual a interface dela, onde ela esbarra na prevenção, qual a diferença, eu acho que, conceitualmente, não está muito claro. A gente está aí, passando por este processo (66Z2).

Eu não saberia especificar uma ação, mas seria um ato que englobaria toda a comunidade que tentaria mudar o pensamento curativo, alguma ação que mostrasse para eles que a promoção é válida, que resolve. Isso seria uma promoção: que englobaria toda a comunidade (28Y5).

Ao refletir sobre os conceitos referentes à promoção de saúde, Castiel $^{10}$ aponta a inconclusão presente, pois as atividades de promoção transitam sobre terrenos teóricos de difícil compatibilização: paternalista versus participativo; individual versus coletivo e com os seguintes enfoques ao longo desses dois eixos: conservador (técnicas persuasivas em saúde), reformista (ação legislativa para a saúde), libertário (aconselhamento pessoal para a saúde) e radical pluralista (educação popular em saúde).
Em alguns discursos percebe-se que o conceito da promoção da saúde é expresso como sinônimo de prevenção de agravos:

Promoção da saúde pra mim, primeiro, é a prevenção, porque a gente tem que estar prevenindo para estar mais tarde colhendo os frutos, e o que chama a atenção no PSF pra mim é isso, não é só tratar a doença, porque eu cheguei aqui e estou só tratando da doença, então está sendo pouca coisa que nós estamos fazendo da prevenção. Conseguir prevenir uma desnutrição, uma anemia, conseguir promover a amamentação até os seis meses de idade, de vida, pra mim a promoção seria mais o lado da prevenção da doença, e hoje em dia nós ainda não chegamos neste objetivo (2Y3).

0 Informe Lalonde, publicado pelo Governo Canadense em 1974, é uma referência no debate sobre a promoção da saúde, tendo influenciado o movimento que emergia na época. Nesse Informe, a promoção da saúde foi considerada uma das várias estratégias de prevenção. No final daquela década, no ano de 1979, um documento do Serviço de Saúde Pública Americano adota o modelo, mas indica a dicotomia conceitual entre promoção da saúde e prevenção de doenças. A promoção da saúde foi definida como um conjunto de ações dirigidas para mudanças do estilo de vida, enquanto a prevenção se referia estritamente à proteção de agravos à saúde. ${ }^{2}$

Os participantes do estudo aproximam-se do conceito de promoção da saúde associando-o a práticas que incidem sobre a qualidade de vida, embora esclareçam que essas práticas ainda são muito incipientes no contexto da atenção à saúde.

Alguns movimentos de promoção à saúde, relacionados a atividades de lazer, atividades físicas, ainda, já aponta... mas você ainda não vê nada na questão de promoção à saúde para as famílias nos aspectos da redução do stress, de stress da vida cotidiana, da pressão econômica, do acesso a..., do acesso aos sonhos, desejos, melhoria das condições de vida etc. Então eu acho que a promoção à saúde ainda é um campo a ser explorado, ainda tá muito mais no desejo, muito mais do que no acesso (12Z2).

Tornou-se lugar-comum, no setor saúde, repetir, com algumas variantes, a seguinte frase: "saúde não é doença, saúde é qualidade de vida". Por mais correta que seja tal afirmativa 


\section{Formação do enfermeiro:desafios para a promoção da saúde}

ela costuma ser vazia de significado e, frequentemente, revela a dificuldade que temos, como profissionais da área, de encontrar algum sentido teórico e epistemológico fora do marco referencial do sistema médico que, sem dúvida, domina a reflexão e a prática do campo da saúde pública. Dizer, portanto, que o conceito de saúde tem relações ou deve estar mais próximo da noção de qualidade de vida, que saúde não é mera ausência de doença, já é um bom começo, porque manifesta o mal-estar com o reducionismo biomédico. Porém, pouco acrescenta à reflexão. ${ }^{11}$

Entre as práticas descritas como de promoção da saúde, os participantes do estudo citam caminhadas; atividades de lazer, cultura e grupos de convivência (artesanato, bailes, festas); atividades com grupos de portadores de doenças crônicas não transmissíveis; reuniões de conselhos de saúde, como oportunidades para acionar novas maneiras de relação entre os profissionais e os usuários.

Admite-se que há diversas conceituações disponíveis para a promoção da saúde reunidas, segundo Buss ${ }^{12}$, em dois grandes grupos. 0 primeiro grupo é aquele em que promoção da saúde consiste em um conjunto de atividades destinadas à transformação de comportamentos dos indivíduos, concentrando componentes educativos relacionados com riscos comportamentais passíveis de mudança (atividades físicas, dietas, hábito de fumar, direção perigosa no trânsito). 0 segundo grupo relaciona saúde a um amplo espectro de fatores relacionados com a qualidade de vida, incluindo-se estilo de vida responsável, oportunidades de educação ao longo da vida, apoio social para famílias e indivíduos.

Czeresnia ${ }^{13}$ afirma que promoção da saúde define-se, tradicionalmente, de maneira bem mais ampla que prevenção, pois enfatiza a transformação das condições de vida e de trabalho que conformam a estrutura subjacente aos problemas de saúde. Nesse sentido, assume-se a saúde em sua positividade o que representa um avanço inquestionável no campo teórico, mas que, no campo da prática, encontra como desafio o fato de que considerar saúde em seu significado pleno implica necessariamente lidar com a noção de vida e com o significado que cada pessoa atribui a ela. Diz respeito, portanto, ao fortalecimento da saúde por meio da construção da capacidade de escolha.

De modo geral, prevalecem, nos discursos, concepções que se aproximam do conceito positivo de saúde, mas não foram percebidos mecanismos que garantam a sua efetividade para a transformação das práticas com garantia de novas relações entre os profissionais e usuários e destes com a gestão. Os participantes aproximam-se da discussão teórica sobre a promoção da saúde sem sinalizar como ela adquire concretude nas práticas de promoção, ou seja, como ocorre a mudança de enfoque da racionalidade preventiva - que atua sobre a doença, transmissão e risco - para uma nova forma que estimula a autonomia e potencializa a saúde dos sujeitos.

Ao analisar as práticas descritas pelos participantes, foram reveladas as relações que eles estabelecem entre promoção da saúde e qualidade de vida; promoção da saúde e cidadania; promoção da saúde e intersetorialidade; promoção da saúde e integralidade e promoção e práticas coletivas. Verifica-se, no relato das práticas, a direcionalidade ao incremento e fortalecimento de ações coletivas, superando as ações dirigidas ao indivíduo, à patologia e aos sinais e sintomas. Entretanto, como mencionado, os participantes revelam dificuldades para a concretização dessas práticas no cotidiano das práticas de saúde:

A promoção à saúde, talvez ela não venha como prioridade do próprio setor saúde, talvez ela venha dos movimentos sociais, venha como falta, não sei. Ou pelos próprios estudantes da área de saúde ou pelas próprias avaliações do serviço, de efetividade do serviço, porque quanto mais se gasta com recuperação... Alguma coisa há de acontecer, não sei de onde que vai vir (34Z2).

Eu acho que a questão da promoção à saúde da população. que a gente vê e assiste muito a questão da demanda espontânea... e essa demanda espontânea vem porque a promoção à saúde, ela não é compreendida e abordada... A questão do planejamento das ações (41W4).

A análise dos dados revela que os profissionais têm centrado forças no atendimento cotidiano da demanda espontânea, sem planejamento e avaliação da efetividade das ações. Manifestaram a marginalização que a promoção da saúde tem sofrido nos serviços de saúde e na abordagem junto à comunidade. Para os entrevistados, existe uma centralidade na doença que os usuários apresentam na demanda espontânea, não havendo espaço para uma oferta organizada de ações, em parceria com a comunidade, que dê conta de ampliar os referenciais da assistência e de proporcionar a continuidade e integralidade do cuidado. Assim, para o discente que chega aos serviços com uma visão mais ampliada, buscando a construção de uma nova prática, com uma possibilidade de "fazer alguma coisa que não sabemos de onde vai vir", a situação salientada no discurso acima ganha significado. 
A falta de participação das comunidades é apontada nos discursos dos entrevistados como um grande desafio para a construção da promoção da saúde no cotidiano dos serviços. Foi apontada, ainda, a insuficiência de mecanismos para lidar com o estresse cotidiano, para contornar a pressão econômica e para estabelecer acesso a "sonhos" e "desejos". Os participantes do estudo, de modo especial os estudantes, revelam essa condição pela forma como se referem aos conselhos de saúde e Associações Comunitárias e de Bairro. Explicitam o entendimento de que esses espaços de participação e controle social não estão sendo ocupados, seja por desconhecimento da população, por desarticulação, por questões culturais orientadas por questões assistencialistas e individualistas ou, ainda, por esses espaços não legitimarem as demandas e interesses coletivos. Há discursos que revelam a compreensão da força da organização da comunidade quando reivindica melhorias nas condições de vida, que podem sinalizar o reforço da ação comunitária, mecanismo que aciona as ações de promoção da saúde:

Acho que pode ser trabalhado isso também com os grupos e ampliar, também, essa discussão da promoção à saúde; só é possível fazer promoção da saúde se eles compreenderem o que que está acontecendo aqui; a comunidade interagir com eles aqui, nesses murinho; que ainda são murinhos, mas que podem deixar de ser... (62W4).

0 reforço da ação comunitária para a participação efetiva e concreta da comunidade, na eleição de prioridades, na tomada de decisões e na elaboração e desenvolvimento de estratégias para alcançar melhor nível de saúde, é fundamental para empoderar a comunidade e favorecer a promoção da saúde. ${ }^{14}$ Além disso, propicia compreender os meios como cada pessoa enfrenta suas necessidades e como, juntas, podem exercitar sua cidadania e serem capazes de produzir transformações em suas realidades, o que requer também práticas para além do setor saúde. Nesse sentido, os entrevistados explicitam a importância da intersetorialidade, de ir para "além dos muros" da unidade de saúde para que a promoção da saúde seja uma vivência concreta. A complexidade que perpassa as ações de promoção da saúde é relatada nos discursos como o grande desafio a ser superado com a articulação intersetorial e o enfoque interdisciplinar:

A promoção da saúde éum tema desafiador porque ela abrange diversos conhecimentos. Se a gente parte do pressuposto de que saúde é um conceito imenso, que envolve lazer, educação, habitação e, eu diria, principalmente, dignidade, então ela é bastante abrangente, desafiadora, difícil, mas ela épossivel... (15X2).

(...) o que a gente vê é, tanto nos serviços de saúde quanto na academia, a discussão da promoção da saúde que está muito aliada à capacidade de interagir com as politicas externas do setor saúde, com a educação básica, com o serviço de assistência social, de controle ambiental; essa questão toda que ainda é muito tímida e, principalmente, para aquela área específica da enfermagem que ainda relaciona a promoção da saúde com, como eu diria, ainda no espaço de controle de doenças (11Z2).

Os discursos sinalizam que as parcerias do setor saúde são estabelecidas com instituições educacionais e pastorais, o conselho tutelar e as associações de bairro. Ainda, que as ações de promoção da saúde acontecem de forma pontual e com pouco movimento em busca de extrapolar os muros das unidades de saúde e ampliar os cenários de ensino e de assistência. Apontam a necessidade de consolidação de políticas que tenham um enfoque intersetorial, o que potencializaria as práticas de promoção da saúde, evitando a fragmentação das demandas e necessidades das pessoas em vários setores.

Como desafios para a efetivação de práticas intersetoriais que possibilitem a promoção da saúde, os participantes do estudo apontaram descontinuidade da presença da universidade, parceira nessas construções, nos diferentes serviços e movimentos sociais. Sinalizaram que essa descontinuidade dificulta o vínculo necessário para a construção de novas práticas.

Eu disse que também exige um movimento diferente e também fica a cargo dos estudantes que virão, e a gente acaba tendo esse mesmo problema de não ter certeza se isso vai continuar. Eu acho que se a universidade não se envolve de uma forma mais consistente fica fragmentado do mesmo jeito; eu acho que é um grande problema, uma crítica que precisa ser pensada (77W4).

(...) termina e a universidade vem aqui só depois que passa um tempo; que a gente vai acabar em abril e só vem em agosto, o que seria quatro meses 


\section{Formação do enfermeiro:desafios para a promoção da saúde}

Silva KL, Sena RR, Grillo MJC, Horta NC

de afastamento, porque a gente não vê muito a continuidade (50W3).

Normalmente, o que uma turma deixa quem continua é a gente, as enfermeiras, a equipe. $A$ gente dá sequência no que o outro grupo deixou; para passar pra frente é um pouco dificil sim (14Y2).

Mesmo assim, a interação entre a instituição de ensino e o serviço de saúde é revelada pelos entrevistados como condição favorável à implementação de aç̃̃es de promoção da saúde e que apoiam a orientação de uma rede intersetorial. Entretanto, apesar de uma tendência de articulação mais estreita entre ensino-serviço, percebe-se que a realidade dos serviços é muito mais dinâmica que a teorização e as construções, na perspectiva de mudança, que ocorrem no ensino. A articulação ainda não se dá de forma efetiva.

Os discursos reforçam a importância da atuação dos estudantes nos cenários dos serviços de saúde, afirmando que são potentes para mobilizar novas práticas assistenciais e de cuidado, com foco na promoção da saúde. Ressaltam, entretanto, que são insuficientes os mecanismos criados pelas instituições de ensino para garantir a continuidade das mudanças realizadas pelos estudantes nos serviços. Assim, mesmo que potentes para imprimir uma nova lógica no modelo tecnoassistencial em saúde, as rupturas e as soluções de continuidade no processo enfraquecem a capacidade das iniciativas disparadas. ${ }^{6}$

Mourão et al. ${ }^{15}$ afirmam que a falta de articulação entre o serviço e a universidade é percebida na descontinuidade, nos períodos de férias acadêmicas, dos projetos iniciados e até na interrupção da oferta de um determinado serviço que era oferecido pelos estudantes. De acordo com os autores, quando ocorre cobrança de continuidade por parte da população, fica a cargo da equipe de profissionais das unidades responderem.

Os participantes do estudo sinalizam que, durante a formação, o enfermeiro tem poucas oportunidades de desenvolver habilidades para a promoção da saúde, seja por dificuldades dos docentes em proporcionar essas experiências ou por serem experiências incipientes e pontuais nos espaços de ensino-aprendizagem. Eles apontam, também, uma insuficiência de discussão teórico-conceitual do tema entre os profissionais, estudantes, professores e usuários:

Na escola, eu acho que o nosso paradigma é muito voltado para a patogênese, (...) eu acho que eles estão no discurso ainda da prevenção e é um discurso que está voltado para a vigilância (...). E se a gente pensar, nós não temos, aqui na escola,
Esc Anna Nery Rev Enferm 2010 abr-jun; 14 (2): 368-376

nenhuma disciplina que trata da Ecologia Humana, que é o primeiro ponto para você discutir a promoção da saúde; e se você não está discutindo esse aspecto, da ecologia humana, e aqui na escola eu não vejo, eu não conheço ainda (...). Então, eu acho que nós temos um desafio muito grande para entender promoção de saúde... (7X1).

Caso as duas escolas-cenário desenvolvam ações e práticas voltadas para o meio ambiente essas não foram apontadas nos discursos dos participantes, o que pode explicar seu papel secundário na formação.

Destaca-se que a organização da universidade brasileira, com arranjos políticos institucionais permeados por conflitos e interesses, nos moldes em que hoje existe, em pouco vem atendendo as necessidades da sociedade em constante mudança, gerando pouca credibilidade junto aos serviços de saúde. ${ }^{15} \mathrm{~A}$ contradição se revela diante do fato de que as discussões da promoção da saúde, no âmbito da formação do profissional enfermeiro, pouco se aproximam das possibilidades visualizadas e implementadas pelos estudantes nos serviços de saúde. As ações de promoção requerem o uso de dispositivos do campo da interdisciplinaridade e intersetorialidade, em geral, pouco discutidas no foco conteudista da sala de aula.

Os professores que exercem cargo de gestão nos cursos explicitaram tentativas de se propiciar, durante a formação, a inclusão de discussões e práticas que contribuam com uma aproximação à promoção da saúde. Apontaram a importância das políticas públicas, na área de educação e saúde, como disparadoras de um processo de mudança na formação do enfermeiro. Contudo, é preciso o envolvimento coletivo de docentes e estudantes para refletir sobre as diferentes práticas de gestão, de assistência e ensino, o que não é de fácil operacionalização.

0 que os discursos revelam é que há uma decisão política de mudança na formação do enfermeiro e que o conceito de promoção da saúde está colocado como uma das diretrizes para essa formação. Há propostas de reorganização de conteúdos e de utilização de metodologias que acionem a incorporação de novas práticas, que não se traduzam na visão linear e classificatória do setor saúde na perspectiva tradicional do processo saúde-doença. Desse modo, como apontado por Falcón et al. ${ }^{16}$, o processo ensino-aprendizagem encaminhado para a incorporação da promoção da saúde na formação do enfermeiro desenvolve-se em uma etapa de crise, indo de um estado de ordem, caracterizado pelo pensamento biologista da saúde, a um estado de desordem, gerado pela necessidade de formação para a promoção da saúde. Essa transição é marcada 
por um caminhar ainda incerto e contraditório, pela universidade, e pelas visões e práticas tradicionais pautadas no que a sociedade entende por saúde.

Durante as visitas aos cenários de aprendizagem, nos serviços e nos espaços comunitários, foram vividos momentos com profissionais, docentes e estudantes que possibilitam afirmar que os discursos dos participantes não retratam a complexa rede de relações e a dinâmica das práticas implementadas pelos estudantes, profissionais e usuários. A análise dos dados levantados nestes cenários apontou que é no cotidiano da assistência que se revelam as possibilidades de promoção da saúde. Falcón et al. ${ }^{16}$, em estudo sobre o cuidado para a promoção da saúde, destacam que os alunos consideram importante, além das aulas teóricas, ter maior contato com a comunidade, uma vez que, para a promoção da saúde, é importante levar-se em conta o conhecimento dos membros da comunidade sobre o processo de saúde-doença, sua maneira de conservar a saúde e de reagir diante da doença.

Munõz \& Cabieses $^{17}$ destacam que a associação entre o meio universitário e a promoção da saúde deve existir como forma de se motivar a comunidade acadêmica para que a universidade incorpore a promoção da saúde em seu projeto. Entretanto, a própria construção das universidades como promotoras da saúde ainda está em um campo permeado por desafios. Nesta construção, as universidades, como espaços sociais, deveriam facilitar ações de promoção de saúde de amplo espectro, dando suporte ao aprendizado e a pesquisa, por meio de um trabalho conjunto voltado para a resolução de problemas que desafiam o bem-estar de quem vive, trabalha, visita ou busca atendimento nessas instituições. ${ }^{18}$

\section{CONSIDERAÇÕES FINAIS}

As concepções e as práticas de promoção da saúde na formação do enfermeiro estão em disputa com projetos hegemônicos, sendo necessário acionar mecanismos para criar um novo modus operandique supere as ações orientadas pelo enfoque biológico. Ainda estão prevalecendo as ações de cunho preventivista que, embora importantes para o setor, não avançam para uma concepção positiva de saúde. Essa situação é referida tanto em relação aos espaços de formação quanto aos espaços de atuação profissional, o que contribui para a permanência de um ciclo vicioso em que teoria e prática reiteram modelos tradicionais de atuação.

Como o docente é tido como uma das figuras centrais na formação e no processo de mudança e inovações curriculares, é fundamental que ele seja capaz de romper com práticas tradicionais, com criticidade e criatividade, e implementar ações à luz de um novo paradigma. Assim, considerando a promoção da saúde como o novo paradigma da saúde coletiva e a imprecisão conceitual sobre promoção trazida nos discursos dos sujeitos, a proposta de romper com as práticas tradicionais é lançada como um grande desafio para os docentes.

Apesar das limitações do estudo, temporal e focal sobre 2 cursos de enfermagem de uma região brasileira, podemos afirmar que a abordagem da promoção da saúde é tomada como decisão política para mudança na formação do enfermeiro, explicitada nos projetos pedagógicos das instituições, cenários do estudo. Entretanto, essa incorporação é incipiente e heterogênea quanto à formulação teórica, indicando a necessidade de ampliação dos espaços de discussão dos conceitos e da operacionalização, em um contexto de integração teoria e prática. Portanto, a construção de uma efetiva integração ensino-serviço coloca-se, também, como um desafio a ser enfrentado, pois os cenários de prática são apresentados como os espaços em que a promoção da saúde é vivenciada durante a formação, talvez a única possibilidade concreta durante esse processo.

Debates sobre políticas públicas intersetoriais voltadas para a melhoria da qualidade de vida, sobre a equidade na produção e no consumo de ações e serviços de saúde e sobre inclusão social e afirmação da cidadania, e outros temas, precisam ser incluídos na formação, envolvendo os profissionais dos cenários de prática.

\section{REFERÊNCIAS}

1. Heidemann ITSB, ALmeida MCP, Boehs AE, Wosny AM, Monticelli M. Promoção à saúde: trajetória histórica de suas concepções. Texto\&Contexto Enferm 2006; 15(2):352-58.

2. Derntl AM, Watanabe HAW. Promoção da saúde. In: Litvoc J, Brito FC, organizadores. Envelhecimento: prevenção e promoção da saúde. São Paulo(SP): Atheneu; 2004. p. 37-46

3. Germano RM. 0 ensino de enfermagem em tempos de mudança. Rev Bras Enferm 2003; 56(4): 365-8.

4 Ministério da Saúde (BR). Política Nacional de Promoção da Saúde. Aprovada pela Portaria $n^{\circ}$ 687, de 30 de março de 2006 Brasília(DF); 2006.

5. Ceccim RB, Feuerwerker LCM. 0 quadrilátero da formação para a área da saúde: ensino, gestão, atenção e controle social. PHISIS: rev saude coletiva 2004; 14(1): 41-65.

6. Silva KL, Sena RR, Grillo MJC, Prado PM. Promoção da saúde como decisão política para a formação do enfermeiro. Rev Esc Enferm USP 2007; 41 (n. esp): 826- 
7. Souza MHN, Paz EPA, Griep RH, Sousa Al, Silva LL da, Paixão AR da. Experiências de ensino-aprendizagem de estudantes de enfermagem em uma comunidade do município do Rio de Janeiro. Esc Anna Nery Rev Enferm 2006 ago:10(2): 251-57.

8. Silva KL, Sena RR. Integralidade do cuidado na saúde: indicações a partir da formação do enfermeiro. Rev Esc Enferm USP 2008; 42(1):48-56.

9. Sena RR, Silva KL, Gonçalves AM, Duarte ED, Coelho S. 0 cuidado no trabalho em saúde: implicações para a formação do enfermeiro. Interface: comunic saude educ 2008; 12(24): 23-34.

10. Castiel LD. Promoção de saúde e a sensibilidade epistemológica da categoria 'comunidade'. Rev Saude Publica 2004; 38(5): 615-22.

11. Minayo MCS, Hartz Z, Buss PM. Qualidade de vida e saúde: um debate necessário. Cienc Saude Colet 2000; 5(1): 7-18.

12. Buss PM. Promoção da saúde e qualidade de vida. Cienc Saude Colet 2000; 5 (1): 163-77.
13. Czeresnia D, Freitas CM, organizadores. Promoção da saúde: conceitos, reflexões, tendências. Rio de Janeiro(RJ): FIOCRUZ; 2003.

14. Oliveira SHS, Monteiro MAA, Lopes MSV, Brito DMS, Vieira NFC, Barroso MGT, Ximenes LB. Estratégias de enfrentamento da pobreza e sua interface com a promoção da saúde. Rev Latino-am Enfermagem 2007; 15(n. esp): 867-73.

15 Mourão LC, Martins RCB, Vieira CM. Análise institucional e educação: reforma curricular nas universidades pública e privada. Educ Soc 2007; 28(98):181-210.

16 Falcón GCS, Erdmann AL, Backes DS. Significados do cuidar na promoção da saúde. Rev Latino-am Enfermagem 2008; 16(3): 419-24.

17 Munõz M, Cabieses B. Universidades y promoción de la salud: cómo alcanzar el punto de encuentro? Rev Panam Salud Publica 2008; 24(2): 139-46.

18 Moysés ST, Krempel MC. Universidade saudável: uma estratégia de promoção da saúde. Olho Mágico 2003 jul/set; 10(3): 83-87.

\section{NOTA}

a Pesquisa financiada pela Fundação de Amparo à Pesquisa do Estado de Minas Gerais, sob processo número 3239/06 e premiada no 59º Congresso Brasileiro de Enfermagem 